\title{
LA REFORMA DE LA LEY DE COSTAS: A PROPÓSITO DE LA STC 233/2015, DE 5 DE NOVIEMBRE DE 2015
}

\author{
Alejandro VillanueVa TuRnes \\ Licenciado en Derecho y Máster en Derecho de las Administraciones e Instituciones \\ Públicas \\ Doctorando en Derecho en la Universidad de Santiago de Compostela \\ Alejandro.villanueva@usc.es
}

Recibido: 17 de mayo de 2016 / Aceptado: 7 de junio de 2016

RESUMEN: A finales del año 2015 se resolvió un recurso de inconstitucionalidad promovido contra la reforma de la Ley de Costas. El Tribunal Constitucional dicta Sentencia haciendo una estimación parcial en relación a lo recurrido y mostrando una preocupación por la temática tratada en particular y la temática medioambiental en general.

RESUMEN: A final de l'any 2015 es va resoldre un recurs d'inconstitucionalitat promogut contra la reforma de la Llei de Costes. El Tribunal Constitucional dicta sentència fent una estimació parcial en relació amb allò recorregut i mostrant una preocupació per la temàtica tractada en particular i les qüestions ambientals en general.

\footnotetext{
ABSTRACT: At the end of 2015 was resolved an action of unconstitutionality against the change in the Coastal Law. The Constitutional Court passes Sentence, the Court does a partial estimate and the Court manifest a concern for the topic covered in particular and for the environmental topic in general.
} 
PAlabras Clave: Ley de Costas - Cambio climático - Interdicción de la arbitrariedad — Principio de irretroactividad — Seguridad jurídica.

PARAULES CLAVE: Llei de costes - Canvi climàtic — Interdicció de l'arbitrarietat — Principi d'irretroactivitat — Seguritat jurídica.

KEY WORDS: Coastal Law - Climate change - Interdiction of arbitrariness Principle of non-retroactivity — Legal certainty.

SUMARIO: I. Introducción. II. Comentario General. 1. En atención a la parte declarada inconstitucional. 2. En atención a la parte declarada constitucional. III. Preceptos constitucionales afectados. 4. Conclusión y reflexión final. 5. Bibliografía.

\section{INTRODUCCIÓN}

En el año 1988 se aprueba la Ley 22/1988, de 28 de julio, de Costas. Esta Ley daba cumplimiento al mandato constitucional del artículo 132 que hace mención a la zona marítimo-terrestre de forma específica en su apartado segundo, cuyo tenor literal es el siguiente:

Son bienes de dominio público estatal los que determine la ley y, en todo caso, la zona marítimo-terrestre, las playas, el mar territorial y los recursos naturales de la zona económica y la plataforma continental.

Tal y como se ha afirmado en distintas ocasiones, la aprobación de esta norma era una necesidad indiscutible teniendo presente la situación litoral española en el momento de su aprobación ${ }^{1}$.

Sin embargo, tal y como ha señalado la Unión Europea en el informe Auken, en lo referido a la protección del litoral, esta Ley no obtuvo una aplicación efectiva ${ }^{2}$. No debe por ello

\footnotetext{
${ }^{1}$ GARCÍA PÉREZ, M., "Reflexiones sobre la Ley de Costas", Anuario da Facultade de Dereito da Universidade da Coruña, $\mathrm{n}^{\mathrm{o}}$ 13, 2009, p. 210.
} 
restársele importancia a la norma, ya que ha sido una de las normas sectoriales de mayor impacto social, y es que la Ley de Costas ha tenido una gran incidencia, siendo rechazadas algunas directrices que contenía por parte de distintos municipios costeros, que intentaron evitar su aplicación en determinados aspectos, como ocurrió con la servidumbre de protección y la prohibición llevar a cabo edificaciones residenciales en ella ${ }^{3}$.

Ahora bien, en el año 2013, se produce un cambio legislativo promovido por el Partido Popular, aprobándose la Ley $2 / 2013$, de 29 de mayo, de protección y uso sostenible del litoral y de modificación de la Ley 22/1988 ${ }^{4}$. Este mismo año, 106 diputados del Partido Socialista presentaron un recurso de inconstitucionalidad ante el Tribunal Constitucional frente a esta reforma.

Del recurso presentado, nace la Sentencia 233/2015, de 5 de noviembre, en la cual el Máximo Intérprete de la Constitución va a considerar que los artículos 1 apartado 39; la Disposición Adicional 4a en sus apartados 1, 2 y 4; y la Disposición Adicional 9a son inconstitucionales y nulos. A su vez, se va a recurrir a la técnica de la interpretación conforme en lo referido a la Disposición Adicional $7^{\mathrm{a}}$ y el Anexo de la Ley, aceptando su constitucionalidad siempre que se entiendan en consonancia a la doctrina constitucional del Fundamento Jurídico 14 de la propia Sentencia.

\section{COMENTARIO GENERAL}

\footnotetext{
${ }^{2}$ Respecto de esto: SÁNCHEZ BLANCO, A., "La delimitación del dominio público marítimo terrestre en la Ley de costas: Incidencia de la legislación de puertos, de navegación marítima, de la normativa comunitaria sobre seguridad marítima, y del enjuiciamiento institucional del estado español por el parlamento europeo en el informe Margrete Auken", SANCHEZ GOYANES, E., El derecho de costas en España, La Ley, Madrid, pp. 339-383, y TORRES ALFONSEA, F. J., "La ocupación del dominio público marítimo-terrestre en España”, Investigaciones geográficas, ${ }^{\circ}$ 50, 2009, pp. 63-91.

${ }^{3}$ MENÉNDEZ REXACH, A., "La Ley de costas veinte años después", VV.AA., La Ley de costas en la jurisprudencia, Ministerio de Medio Ambiente y Medio Rural y Marino, Madrid, 2010, p. 15. Al mismo tiempo debe confrontarse sobre el tema la siguiente obra: NOGUERA DE LA MUELA, B., Las servidumbres de la Ley de Costas de 1988, Marcial Pons, Madrid, 1995.

${ }^{4}$ En relación con esta reforma confróntese: NÚÑEZ LOZANO, M. C., La reforma de la Ley de Costas de 2013, Tirant lo Blanch, Valencia, 2013.
} 
En esta parte se procederá a comentar la Sentencia con carácter general, dividiendo la misma en aquellos preceptos que han sido efectivamente invalidados por el Tribunal, $\mathrm{y}$ aquellos que han sido considerados correctos y compatibles con los preceptos constitucionales.

\section{En atención a la parte declarada inconstitucional}

Como acabamos de adelantar, el Tribunal Constitucional va a estimar parcialmente el recurso y declarar inconstitucional la reducción de la protección medioambiental de la costa de la isla de Formentera. La Ley recurrida establecía que el territorio insular tenía un dominio público cuantitativamente menor en relación con el resto del litoral español. La propia resolución considera que el deceso de protección que se le da a la rivera de la isla de Formentera no es justificable en comparación con el resto del archipiélago.

En un primer lugar se hace constar la imposibilidad del legislador de apartar del dominio público marítimo-terrestre ningún bien que pertenezca al mismo, teniendo estos bienes públicos, que gozar de una especial protección debido a su extraordinaria singularidad.

E1 Tribunal Constitucional realiza un exhaustivo análisis sobre donde comienza el dominio público marítimo-terrestre, considerando que se trata, donde se produce el contacto de la zona litoral con las mareas y otros factores que sean producto de la mano del hombre. En este punto, y con el tono más científico que puede caracterizar al Tribunal, éste va a instar a medir la extensión de la costa empleando tres aspectos, siendo éstos la experiencia, la observación y la razón, de tal manera que no se mida en base a criterios arbitrarios o abusivos.

Lo que acaba de decirse se va a relacionar con la idea de considerar que los límites del dominio público no son inmutables ni tampoco quedan inalterables para siempre, sino que pueden cambiar, evolucionar y adaptarse a las nuevas necesidades o a los nuevos fenómenos como el cambio climático, considerado como "la más relevante constatación científica aparecida desde 1988".

\footnotetext{
${ }^{5}$ Esto aparece especificado en los Antecedentes de Hecho primero a). Hay que tener presente que para afirmar esto se realiza un apoyo documental en los datos aportados por el Grupo de Expertos sobre el Cambio Climático de la ONU en el estudio "Cambio climático 2007: informe de síntesis", considerando dichos
} 
El Alto Tribunal se decanta por aceptar que el cambio climático es uno de los problemas medioambientales actuales más importantes a los que la sociedad tiene que hacer frente y, no simplemente se dedica a afirmar dicha realidad, sino que toma partido, situándose del lado de la lucha contra el cambio climático protegiendo las costas de la península para reducir el posible riesgo que se produciría en caso de que no se diera el amparo suficiente ${ }^{6}$.

Lo que la Sentencia hace es declarar que determinados preceptos que forman parte de la reforma a la Ley de Costas son arbitrarios, abusivos y no suponen una defensa respecto del medio ambiente a la vez que provocan una regresión de las playas, produciéndose también en algunas ocasiones, inundaciones en lugares cercanos a las mismas.

Uno de los temas candentes de la Sentencia objeto de análisis no es otro que el deslinde de la isla de Formentera. En este punto, creemos conveniente realizar una referencia en relación con la institución del deslinde.

El deslinde administrativo ha sido definido por la doctrina como aquella institución cuya utilidad se encuentra en la declaración de los límites entre aquellos bienes que son de la propia Administración y aquellos que son de los particulares "satisfaciendo de esta forma la facultad de exclusión dimanante del derecho de propiedad"7 . Dicho esto, y refiriéndonos al deslinde de $\operatorname{costas}^{8}$, que es el regulado en la norma, nos encontramos con que se trata de un instrumento jurídico que va a tener como objetivo

establecer los límites interiores del demanio marítimo - terrestre, marcando la línea de separación entre los terrenos de dominio público y los terrenos de propiedad privada; pero también es [...] un acto de concreción en cada lugar determinado del litoral de los criterios que definen los bienes marítimos, la ribera del mar, y que sitúan las zonas de servidumbres, en un proceso descendente y sucesivo de lo general y abstracto a lo particular y concreto marcado por la Ley y el Reglamento de Costas 9 .

expertos que el proceso es un hecho cierto que puede dejar importantes perjuicios en las costas bajas y, de forma especial, el mar Mediterráneo.

${ }^{6}$ Fundamento Jurídico 3.

${ }^{7}$ RIVERO ISERN, E., El deslinde administrativo, IGO, Sevilla, 1967, p. 167.

${ }^{8}$ En relación con esto resulta sumamente interesante: GONZÁLEZ - VARAS IBÁÑEZ, S., El deslinde de las costas, Marcial Pons, Madrid, 1995.

${ }^{9}$ HORGUÉ BAENA, C., El deslinde de costas, Tecnos, Madrid, 1995, p. 318. 
Junto con esto nos vamos a encontrar con que se va a configurar como un acto que presenta una eficacia general y erga omnes, materializándose mediante la declaración de inexistencia de los derechos de propiedad de particulares o su pérdida, clarificando la situación $^{10}$.

Hecho este breve apunte, se declara en la Sentencia, que la Disposición Adicional $4^{\text {a }}$ de la Ley objeto de recurso, es inconstitucional por ser totalmente arbitraria, ya que eliminaba el dominio público por la especial configuración geomorfológica y en relación con la pleamar y bajamar de las mareas respecto de las $\operatorname{costas}^{11}$. En este sentido, también se anula el plazo de dos años que tenía la Administración para llevar a cabo el citado deslinde y aquel apartado que pretendía reintegrar bienes a los propietarios que se vieran afectados por el citado deslinde, en caso de que tuvieran un título antes de la promulgación de la Ley.

La propia resolución inadmite en el mismo sentido la exclusión de zonas del permiso que se concede para inundar de forma artificial zonas del litoral con motivo de las obras que se puedan realizar $^{12}$. Y en tal sentido se anula la Disposición de la Ley 22/1988 que había permitido considerar legal una depuradora en Cantabria que, previamente, había sido declarada ilegal por el Tribunal Supremo en una resolución previa.

Asimismo, el Tribunal Constitucional entiende como ilegal la Disposición Adicional 9a en la que se indica que es necesario prestar atención a las circunstancias económicas que se daban durante el año 2013 y que impedían que se pudiera invertir y realizar gasto público ${ }^{13}$. Por lo tanto a tenor de la derogada Disposición las instalaciones de depuración de aguas construidas antes de la Ley se podrían mantener donde estuvieran emplazadas, permitiendo que su actividad se mantuviera durante un período de tiempo en las condiciones de servicio y explotación y siempre que se respetase la normativa medioambiental.

\footnotetext{
${ }^{10}$ HORGUÉ BAENA, C., El deslinde de costas, Tecnos, Madrid, 1995, pp. 318 - 324.

${ }^{11}$ Sobre esta Disposición, y siguiendo la línea marcada por la resolución comentada, también se pronuncia el Tribunal Constitucional en su Sentencia 57/2016, de 17 de marzo.

${ }^{12}$ Fundamento Jurídico 3.

${ }^{13}$ Lo referido a parte se va a seguir en la Sentencia 57/2016, de 17 de marzo, en la cual también se impugna la mencionada Disposición.
} 
La Sentencia invalida la segunda parte de la misma Disposición en la que una vez recuperada la estabilidad económica se debería reemplazar las correspondientes construcciones ${ }^{14}$.

El Alto Tribunal considera que la reubicación de las correspondientes instalaciones debe ser resultado de una resolución judicial, considerando, como no podía ser de otra forma teniendo en cuenta el argumento, que resulta incompatible con el artículo 132 de la Carta Magna el hecho de encorsetar la actividad judicial haciéndola depender de una voluntad política.

En términos del fallo se trata de un acto de “arbitrariedad prohibida al legislador". La resolución judicial considera que las circunstancias económicas no son suficientemente válidas para realizar esta discriminación con respecto del resto del dominio público marítimo-terrestre, suponiendo un quebrantamiento de toda la Ley y jurisprudencia previa.

En este sentido el pronunciamiento del Tribunal Constitucional hace hincapié en la importancia que tiene la costa dentro del Estado español, siendo un elemento de gran relevancia para el medio ambiente del territorio nacional, que otorga una gran diversidad al espacio y que por ello es merecedor de ser objeto de una defensa profunda y protección ${ }^{15}$.

También se hace mención a que únicamente se permitirá la ocupación de este dominio público cuando las actividades o instalaciones tengan, por su naturaleza, la necesidad de establecerse en ese punto exacto y no puedan tener otra ubicación.

Un aspecto a tener en consideración es que, el Tribunal Constitucional no va a declarar contra legem otras Disposiciones como la disminución de la zona de servidumbre de cien a veinte metros en los núcleos urbanos, el nuevo régimen de actividades autorizadas en las playas o la extensión de las concesiones, hasta setenta y cinco años, de las casas, que si bien han sido construidas legalmente antes de la entrada en vigor de la Ley de Costas, con la nueva normativa no estarían dentro del marco de la legalidad normativa.

\footnotetext{
${ }^{14}$ Fundamento Jurídico 15.

${ }^{15}$ Hay que tener presente que dicha relevancia también puede observarse en que la costa supone un total de $7905 \mathrm{~km}$ teniendo en cuenta el litoral peninsular, los archipiélagos canario y balear y las ciudades autónomas de Ceuta y Melilla.
} 
En lo relativo a la Disposición Adicional 7a , como ya adelantábamos al inicio, se hace una interpretación conforme respecto de la misma. Esta Disposición suponía la exclusión de determinados núcleos de población del dominio público marítimo - terrestre. En este punto, el Tribunal recuerda que antes de proceder a declarar la inconstitucionalidad de un precepto, es necesario determinar si existen distintas interpretaciones del mismo, siendo alguna de ellas conforme a la Carta Magna, o no ${ }^{16}$. El Constitucional manifiesta que entendiendo esta Disposición conforme a la Constitución Española, ello va a suponer que sus consecuencias no van a tener una extensión de tipo jurídico a la regulación de aquellos núcleos de población que aparecen excluidos del dominio público marítimo-terrestre en el Anexo de la norma, siendo su identificación recogida en la Ley lo que provoca su virtualidad. Ahora bien, se señala también que hay que prestar atención a lo indicado en el artículo 18.2 de la Ley de Costas, ya que este precepto nos indica que la desafección debe hacerse de forma expresa, siendo imprescindible que antes de hacerla, se practique el deslinde o los deslindes que correspondan, y en la forma que corresponda en atención al reglamento de costas. En palabras del Tribunal,

La disposición impugnada no excluye la aplicación, caso por caso, de todos estos requisitos, que constituyen una exigencia previa e imprescindible para que la situación jurídica registral tanto de los bienes de dominio público como de las fincas colindantes no perturbe la seguridad jurídica garantizada por el art. 9.3 CE. Del mismo modo, la identificación ope legis de los terrenos que han perdido sus características naturales no se extiende a excluir la verificación, en cada caso, de que dicha pérdida determina también que ya no son necesarios para la protección o utilización del dominio público, según lo previsto en el art. 17 LC, que exige la previa declaración de innecesariedad. Todas estas operaciones, lógicamente, requieren la adopción de las correspondientes resoluciones administrativas, siempre susceptibles como ya hemos dicho de control en vía jurisdiccional, como impone el art. $106.1 \mathrm{CE}^{17}$.

\footnotetext{
${ }^{16}$ Para ello invoca su Sentencia 148/2011, de 28 de septiembre.

${ }^{17}$ Fundamento Jurídico 14. Cabe advertir que esta disposición fue tratada de nuevo en la Sentencia del Tribunal Constitucional 57/2016, de 17 de marzo. En esta última Sentencia, el motivo de la impugnación es el mismo que en el recurso resuelto por la resolución objeto de comentario principal aquí, sin embargo se invoca un motivo adicional, siendo este una discriminación para determinados núcleos que, teniendo las mismas condiciones que los que aparecen excluidos, no se le aplica esta exclusión. Pero el Tribunal consideró que con independencia de los ya excluidos, el precepto es constitucional ya que con independencia de los ya excluidos,
} 
Debe aclararse que, a pesar de que en la Sentencia que se está analizando, no se hace mención al apartado 2 de la Disposición Adicional $8^{\text {a }}$, esta ha sido objeto de una interpretación conforme por parte del Tribunal Constitucional en la Sentencia 28/2016, de 18 de febrero. Esta Sentencia resuelve un recurso de inconstitucionalidad planteado por el Gobierno de la Generalitat de Cataluña ante distintas partes de la Ley de Costas, de las cuales el Alto Tribunal únicamente tendrá en consideración lo planteado en relación a esta Disposición, desestimando el resto del recurso. En relación con este apartado segundo de la Disposición Adicional $8^{\mathrm{a}}$. La impugnación se basa en dos motivos, el primero de ellos relativo a la imposición de la realización de un plan de adaptación de los terrenos de dominio público marítimo-terrestre que se le haya asignado a la Comunidad Autónoma y de las estructuras construidos en ellos con la finalidad de enfrentarse al fenómeno del cambio climático.

Y el segundo referido a la necesidad de presentar ante el Ministerio de Agricultura, Alimentación y Medio Ambiente este plan. En relación con el primer motivo, el Tribunal no duda en desestimarlo, ya que tratándose de un mandato que se encuadra en la temática del medio ambiente, el Estado va a tener la competencia para establecer la normativa básica, atendiendo al artículo 149.1.23 de la Constitución.

En relación con el segundo motivo, nos encontramos con que se admite la aprobación por parte del Estado pero

sin que en ningún caso pueda extenderse al modo de disponer y configurar las infraestructuras autonómicas, que queda fuera del ámbito de aprobación estatal circunscrito, como se ha dicho, a los efectos de asegurar que el mencionado plan de adaptación cumpla la finalidad de garantizar la protección y defensa de las condiciones medioambientales del demanio frente al cambio climático ${ }^{18}$.

\section{En atención a la parte declarada constitucional}

cualquier otro va a poder recibir esta condición siguiendo los expedientes administrativos que se prevén legalmente (Fundamento Jurídico 9).

${ }^{18}$ Fundamento Jurídico 7. Esto será reiterado por el Tribunal Constitucional en su Sentencia 57/2016, de 17 de marzo. 
Llegados a este punto, debe advertirse que van a existir distintos preceptos de la Ley recurrida que, a pesar de ser considerados dignos de una declaración de inconstitucionalidad por parte de los recurrentes, van a ser declarados conformes a la Constitución y por lo tanto continúan en vigor. Estamos hablando de los apartados 2, 3, 10, 11, 12, 40 y 41 del artículo 1, el artículo 2, las Disposiciones Adicionales 2, 5 y 6 y la Disposición Transitoria 1.

Haciendo un breve análisis de lo más relevante de ellos nos encontramos que el artículo 1.2 hace una remisión reglamentaria, considerando el Alto Tribunal que dicha remisión no va a suponer una alteración del criterio sustantivo que se emplea para establecer el límite interior de la zona marítimo - terrestre en atención a la referencia de las olas ${ }^{19}$. Siguiendo el tenor literal de la Sentencia, ésta expone que

[S]e limita a remitir la concreción de este criterio decisor, netamente empírico y, por definición, variable tanto en el espacio como en el tiempo, a una normativa que responda al conocimiento técnico, en constante evolución. Con ello no hace sino incrementar las garantías de rigor, objetividad y homogeneidad en la práctica de los deslindes, coadyuvando asimismo al control jurisdiccional de la legalidad de la actuación administrativa ${ }^{20}$.

En lo referente al artículo 1.3, que va a excluir, de las zonas marítimo - terrestres los terrenos que sean inundados de forma artificial y controlada en tanto que previamente a ese hecho no pertenecieran al dominio público. Este último inciso referido a su situación previa a la inundación, es lo que salva la constitucionalidad del precepto, ya que ello va a suponer que

$[\mathrm{N}] \mathrm{o}$ quedan afectados por la exclusión los terrenos naturalmente inundables, que son en todo caso zona marítimo-terrestre, de dominio público por imperativo constitucional $^{21}$.

\footnotetext{
${ }^{19}$ Hay que aclarar que en lo relativo a este precepto, el Tribunal Constitucional va a mantener su posición en posteriores Sentencias como la Sentencia 6/2016, de 21 de enero o la Sentencia 57/2016, de 17 de marzo, que siguen la misma argumentación que se expone aquí.

${ }^{20}$ Fundamento Jurídico 3.

${ }^{21}$ Fundamento Jurídico 3.
} 
En el caso del artículo 1.10, que fija una anchura de 20 metros para las zonas de servidumbre de protección en determinados tramos, la declaración de constitucionalidad se vuelve coherente de acuerdo con la doctrina anterior del propio Tribunal, ya que, haciendo referencia a su Sentencia 149/1991, considera que no se incurre en inconstitucionalidad y que

la fijación de la zona de servidumbre de protección en 100 metros como regla general era y es compatible con el establecimiento, en más, pero también en menos, de márgenes de flexibilidad que tengan en cuenta la realidad preexistente (disposición transitoria tercera LC) o las diversas características físicas de cada tramo de la costa ${ }^{22}$.

El artículo 1.11 provoca, entre otras cosas, un cambio en la prohibición de actividades que supongan la destrucción de yacimientos áridos, limitándose dicha prohibición a los naturales o no consolidados. Al mismo tiempo, este precepto también incluye la publicidad de las actividades o las instalaciones que se permiten y son compatibles con la servidumbre de protección. Respecto de ello, el Máximo intérprete de la Lex Superior considera que se trata de un mandato constitucional y además llega a señalar que forma parte de

[L]a libertad de configuración del legislador, que se proyecta con mayor intensidad cuando se trata de regular no ya el régimen de los bienes de dominio público marítimoterrestre, que en sus líneas maestras figura en el art. 132 CE como límite infranqueable, sino las limitaciones que afectan a los predios sitos en la franja adyacente; los terrenos contiguos a la ribera del $\operatorname{mar}^{23}$.

El artículo 1.12, que incide en la diferenciación, en las zonas de playa, entre tramos naturales y urbanos se considera como válido teniendo en cuenta que el legislador va a tener un margen bastante amplio para poder apreciar la adopción de aquellas medidas que se requieran para que las características de estos bienes sean salvaguardadas, siendo esta una obligación derivada del artículo 42 y 132.2 de la Carta Magna ${ }^{24}$.

\footnotetext{
${ }^{22}$ Fundamento Jurídico 4.

${ }^{23}$ Fundamento Jurídico 5. Esta posición es reiterada en la Sentencia del Tribunal Constitucional 6/2016, de 21 de enero.

${ }^{24}$ Fundamento Jurídico 6. Al igual que sucedía con el 1.11, con este precepto el Tribunal Constitucional vuelve a mantenerse fiel a la doctrina aquí expuesta en la misma resolución 6/2016, de 21 de enero, en la 28/2016 de 18 de febrero y en la 57/2016, de 17 de marzo.
} 
El artículo 1.40 que se encarga de modificar la Disposición Transitoria 4 y que consistía, dicho de forma concisa, en admitir las obras de reparación, mejora, consolidación y reparación, mientras éstas no llevasen consigo un aumento de volumen, de altura ni de superficie de aquellas construcciones que ya existiesen, es un precepto válido, y es que tal y como señala el Alto Tribunal,

$[R]$ ecaen sobre obras o instalaciones existentes o autorizadas con anterioridad a su entrada en vigor, bien porque contaran con previa autorización o concesión conforme a la Ley de costas de 1969, bien porque, sin disponer de dichos títulos, hayan sido legalizadas por razones de interés público, según lo dispuesto en el apartado 1 de esta disposición, que no experimenta modificación. No se consiente el aumento de su volumen, altura o superficie, y no se altera la duración de las concesiones en zona de dominio público, la garantía de la servidumbre de tránsito o, en fin, el régimen general vigente en la zona de servidumbre de protección. Al margen de la valoración que merezca esta regulación desde vertientes diferentes a la estricta perspectiva jurídicoconstitucional, no cabe pues apreciar que en modo alguno se desborde el margen de configuración del que dispone el legislador ${ }^{25}$.

En lo que respecta al artículo 1.41, éste va a introducir la Disposición Adicional 10 regulando las urbanizaciones marítimo-terrestres, impugnándose por conexión la Disposición Adicional $6^{\mathrm{a}}$ que prevé el reintegro a los titulares, inscritos en el Registro de la Propiedad, del dominio de los terrenos de las urbanizaciones que pierdan el carácter demanial. En este caso el Tribunal establece que no se incurre en inconstitucionalidad por diversos motivos, así pues, se va a incorporar al dominio público aquellos terrenos de titularidad privada que hayan quedado inundados, aunque se prevé una excepción, y es referida a aquellos que tengan por objetivo el estacionamiento náutico de carácter individual y privado ${ }^{26}$. De esta manera, se hace referencia a que

[S]e trata por tanto de una regulación que preserva en lo fundamental el carácter demanial de los terrenos inundados que, por su condición de canales navegables, presentan una necesaria continuidad física con el dominio público preservado por el art. 132.2 CE al quedar en comunicación permanente con la zona marítimo-terrestre y el

\footnotetext{
${ }^{25}$ Fundamento Jurídico 8.

${ }^{26}$ Este precepto es tratado también en la Sentencia 28/2016, de 18 de febrero, en la que el Tribunal desestima en base a los mismos argumentos su impugnación.
} 
mar territorial, lo que los hace sensibles a los fenómenos naturales propios de la dinámica litoral. La limitada excepción de los estacionamientos náuticos no desborda el margen de configuración legal del que dispone el legislador, y puede considerarse acorde con la citada doctrina ${ }^{27}$.

Al mismo tiempo, el precepto exige que las urbanizaciones marítimo - terrestres tengan un instrumento de ordenación territorial o urbanística, no llevando aparejado ello una traslación decisoria a la Administración autonómica, sino que se trata de una concurrencia de potestades en relación al mismo espacio físico. A su vez, aquellas obras destinadas a la construcción de los canales navegables y a los estacionamientos náuticos van a requerir el título administrativo correspondiente sin que puedan llevarse a cabo en zonas de costa que constituyan espacios protegidos o playas, señalándose en la resolución que cuando no haya una regulación legal de carácter específico para estas urbanizaciones, se va a proceder a la aplicación de aquellas disposiciones legales generales que se contienen en la propia Ley de Costas encargadas de las obras en zonas de dominio público y en la zona de servidumbre ${ }^{28}$.

El artículo 2 está referido a la prórroga de las concesiones demaniales. En primer lugar, el Alto Tribunal hace una reflexión recordando la inexistencia de la perpetuidad del uso privativo en lo referido al dominio público. Dice el Tribunal que

[L]a extinción de una concesión no implica necesariamente la recuperación del uso general del dominio público, y que la prórroga es condición necesaria, pero no suficiente, para la continuación de la actividad ${ }^{29}$,

Advirtiendo en este punto que no hay una argumentación suficiente para considerar el precepto contrario al principio constitucional de interdicción de la arbitrariedad. Al mismo tiempo se señala que la posible contradicción de la norma respecto de la Directiva 2006/123/CE, del Parlamento Europeo y del Consejo, de 12 de diciembre de 2006, o en atención a los criterios empleados por la Comisión Nacional de los Mercados y la Competencia, no son válidos para determinar la constitucionalidad o inconstitucionalidad del precepto. Determina asimismo que

\footnotetext{
${ }^{27}$ Fundamento Jurídico 9.

${ }^{28}$ Fundamento Jurídico 9.

${ }^{29}$ Fundamento Jurídico 10.
} 
[E]n cuanto al Derecho comunitario europeo, la tarea de garantizar su recta aplicación por los poderes públicos nacionales es "una cuestión de carácter infraconstitucional, y por ello excluida tanto del ámbito del proceso de amparo como de los demás procesos constitucionales" (por todas, STC 41/2002, de 25 de febrero, FJ 2), si bien también hemos manifestado que "las exigencias derivadas del Derecho de la Unión no pueden ser irrelevantes a la hora de establecer los márgenes constitucionalmente admisibles de libertad de apreciación política de que gozan los órganos constitucionales" (STC $1 / 2012$, de 13 de enero, FJ 9) ${ }^{30}$.

Con esto presente, se hace referencia a la Directiva 2014/23/UE, del Parlamento Europeo y del Consejo, de 26 de febrero de 2014 relativa a la adjudicación de contratos de concesión la cual dentro de su objetivo de conseguir un sistema de adjudicación de concesiones no discriminatorio y efectivo para todos los operadores la Unión Europea, no incluye los acuerdos que tengan por objeto el derecho a explotar determinados recursos o parajes públicos por parte de un operador económico donde el Estado, el poder o la entidad adjudicadora se va a encargar de establecer aquellas condiciones de carácter general para su uso sin que se contraten servicios u obras concretas ${ }^{31}$.

Por lo que se refiere a la Disposición Adicional $2^{\mathrm{a}}$ y $5^{\mathrm{a}}$, en ambas se invoca una vulneración del artículo 9.3 de la Constitución Española. Hay que tener presente que la primera de estas Disposiciones se presentaba inconstitucional por los recurrentes en base a que la revisión del deslinde va a incidir en situaciones ya consolidadas y también en la integridad del dominio público natural, cosa que es rechazada por el Tribunal señalando el carácter ordinario de la actividad del deslinde ${ }^{32}$. En la segunda de las Disposiciones, se establece el reintegro del dominio de terrenos que dejen de formar parte del dominio público marítimo terrestre, cosa que no sólo no vulnera el artículo 9.3 sino que ante la posibilidad de que se pueda afectar al principio de cosa juzgada, el Tribunal señala que para saber si se afecta al mismo es necesario hacer un análisis para determinar si el precepto legal conlleva una revisión de sentencias firmes, cosa que no sucede en este caso ${ }^{33}$.

\footnotetext{
${ }^{30}$ Fundamento Jurídico 10.

${ }^{31}$ Fundamento Jurídico 10.

${ }^{32}$ Fundamento Jurídico 11.

${ }^{33}$ Fundamento Jurídico 13.
} 
En lo que respecta a la Disposición Transitoria $1^{\mathrm{a}}$, ésta no hace otra cosa que determinar el régimen de aplicación de la Disposición Transitoria $3^{\mathrm{a}}$ que establece el régimen que se aplica a aquellos terrenos calificados de suelo urbano en el momento en el que la Ley de 1988 entraba en vigor. El Tribunal basa la no declaración de inconstitucionalidad en un doble motivo. El primero de ellos es que el principio de seguridad jurídica no se va a ver vulnerado, en primer lugar porque las condiciones nuevas y la litigiosidad a la que pudieran dar lugar no supone tal vulneración y es que atendiendo a la Sentencia del Tribunal Constitucional 227/1988, de 29 de noviembre, la seguridad jurídica no va a suponer que unas condiciones o requisitos que se han impuesto en un momento dado deban mantenerse de forma indefinida, dado que se han puesto en relación con unas circunstancias y momentos $\operatorname{concretos}^{34}$, sumado a esto, lo establecido en la Disposición está en concordancia con la jurisprudencia que ha ido marcando el Tribunal Supremo. El segundo es que no se vulneran competencias autonómicas, esto se basa en que la competencia es estatal en atención al artículo 149.1.1 de la Constitución Española, y que la Comunidad Autónoma cuando no tiene competencias, no va a poder regular, ni siquiera copiando la literalidad de la norma estatal. Además, va a señalar el Tribunal lo siguiente:

la norma estatal que ahora examinamos respeta el marco competencial tanto en su dimensión normativa como ejecutiva, al fijar el completo régimen jurídico transitorio, deferir a las competencias urbanísticas de las Comunidades Autónomas únicamente la delimitación o clasificación del suelo que en estos núcleos o áreas pueda ser considerado como urbano, y preservar la competencia estatal a través de la técnica del informe favorable en lo concerniente a la integridad y defensa del dominio público marítimo-terrestre ${ }^{35}$.

\section{PRECEPTOS CONSTITUCIONALES AFECTADOS}

Llegado a este punto y una vez analizado el contenido de la Sentencia que declara la inconstitucionalidad de ciertos preceptos de la Ley de Costas, se procederá a realizar un

\footnotetext{
${ }^{34}$ Fundamento Jurídico 10.

${ }^{35}$ Fundamento Jurídico 16. Hay que aclarar que esta Disposición también ha sido recurrida posteriormente, continuando su criterio el Tribunal y desestimando dicha impugnación, por lo que debe confrontarse la Sentencia del Tribunal Constitucional 6/2016, de 21 de enero, y la 57/2016, de 17 de marzo.
} 
análisis breve de todos aquellos preceptos constitucionales que pueden verse quebrados por la actuación del ejecutivo.

En primer lugar, la norma con rango legal contradice el principio de irretroactividad e interdicción de la arbitrariedad del artículo 9.3 de la Carta Magna. En este sentido la Sentencia del Tribunal Constitucional 112/2006, de 5 de abril, expone que

[L]a interdicción absoluta de cualquier tipo de retroactividad conduciría a situaciones congeladoras del ordenamiento contrarias al art. 9.2 CE (por todas, SSTC 6/1983, de 4 de febrero, FJ 3; y 126/1987, de 16 de julio, FJ 11) y que dicha regla de irretroactividad no supone la imposibilidad de dotar de efectos retroactivos a las leyes que colisionen con derechos subjetivos de cualquier tipo, sino que se refiere a las limitaciones introducidas en el ámbito de los derechos fundamentales y de las libertades públicas o en la esfera general de protección de la persona ${ }^{36}$.

Hay que entender que son los artículos de la Sección $1^{\mathrm{a}}$ del Capítulo $2^{\mathrm{o}}$ del Título $1^{\mathrm{o}}$ de la Constitución los únicos que pueden ser objeto de la alegación del principio de irretroactividad.

Por lo tanto, si tenemos en cuenta la doctrina constitucional y entendemos que el principio de irretroactividad está vinculado a los derechos subjetivos y no en la esfera patrimonial de los particulares afectados vemos que no hay nexo que una el imperativo constitucional con el ilícito del Gobierno. Por ello, en ningún caso el dominio público puede ser objeto de verse afectado por el principio de irretroactividad.

Sin embargo el principio de interdicción de la arbitrariedad parece verse mucho más afectado. La Sentencia considera que la arbitrariedad debe basarse en que no haya diferencias en el régimen jurídico en función de la legalidad originaria de las urbanizaciones marítimo -terrestres.

La Sentencia del Constitucional 27/1981, de 20 de julio, establece que

[E]l acto del Legislativo se revela arbitrario, aunque respetara otros principios del 9.3, cuando engendra desigualdad. Y no ya desigualdad referida a la discriminación -que ésta concierne al artículo 14-, sino a las exigencias que el artículo 9.2 conlleva, a fin de promover la igualdad del individuo y de los grupos en que se integra, finalidad que, en

\footnotetext{
${ }^{36}$ Fundamento Jurídico 17.
} 
ocasiones, exige una política legislativa que no puede reducirse a la pura igualdad ante la ley $^{37}$.

Esta potestad jurisdiccional entiende que no se puede modificar los criterios adoptados con anterioridad, a no ser que se haga con plena consciencia y argumentando razonablemente el cambio de criterio.

El artículo 9.3 vuelve a ver violado en lo relativo a la inseguridad jurídica derivada de la total justificación y claridad al llevar a cabo las medidas que ha desarrollado sin realizar una clara explicación sobre los criterios que emplea para hacer una diferencia entre unos y otros elementos.

La seguridad jurídica es lo que la Sentencia del Tribunal Constitucional 227/1981 define como una

[S] uma de certeza y legalidad, jerarquía y publicidad normativa, irretroactividad de lo no favorable, interdicción de la arbitrariedad, pero que, si se agotara en la adición de estos principios, no hubiera precisado de ser formulada expresamente. La seguridad jurídica es la suma de estos principios, equilibrada de tal suerte que permita promover, en el orden jurídico, la justicia y la igualdad, en libertad ${ }^{38}$.

Esto quiere decir que la seguridad jurídica supone que el legislador debe ser claro, evitando la confusión normativa y procurando que la materia legislada se aleje de provocar situaciones confusas. El hecho de legislar en materia de medioambiente empleando términos vagos, como la recuperación económica, sin dejar claro qué momento se supone que esta se producirá o qué condiciones son las que se considerarían para entender que la recesión ha terminado, supone un ejercicio pereza legislativa en el mejor de los casos o maleficencia en el peor.

Por último el Tribunal alude a la protección del medio ambiente y la conservación del mismo en concordancia con el artículo 45 de la Constitución. La protección ambiental es uno de los aspectos más innovadores de la Constitución y nuestro país uno de los primeros que tratan esta materia, por lo tanto la protección ambiental no es más que el derecho que

\footnotetext{
${ }^{37}$ Fundamento Jurídico 10.

${ }^{38}$ Fundamento Jurídico 10.
} 
tienen las personas de disfrutar del "derecho inalienable a habitar en su entorno de acuerdo con sus características culturales" 39 .

\section{CONCLUSIÓN Y REFLEXIÓN FINAL}

Después de todo lo dicho y como punto final, debemos hacer una breve recapitulación acompañada con una serie de reflexiones finales.

La Ley del año 2013 se esperaba como una oportunidad de actualizar la Ley de Costas de 1988, adaptándola a los nuevos tiempos. No obstante, parece dudoso que la reforma que se ha llevado a cabo pueda ser calificada de positiva y adecuada, y prueba de ello es la Sentencia 233/2015. Esta Sentencia no sólo es la primera en examinar la Ley del 2013, sino que es la resolución más importante de las que ha dictado el Alto Tribunal en relación con la misma.

Esta importancia radica no solo en tanto en cuanto se trata de la resolución que más preceptos examina de la norma, sino también en que se trata de un pronunciamiento que marca las pautas de los restantes que se han producido en torno a la reforma, como son la Sentencia del Tribunal Constitucional 6/2016, de 21 de enero, la 28/2016, de 18 de febrero, y la 57/2016, de 17 de marzo.

Con la Sentencia 233/2015, el Tribunal Constitucional muestra una postura protectora con el litoral. Esto se manifiesta no sólo en la declaración de inconstitucionalidad del deslinde de la Isla de Formentera, que es, sin duda, uno de los puntos clave sobre los que vertebra la resolución, sino también en otros puntos como la no exclusión del dominio público marítimo-terrestre de aquellas zonas que se inundan artificialmente y de forma controlada a raíz de instalaciones $\mathrm{u}$ obras que se llevan a cabo a tal efecto, que es donde nos encontraríamos, por ejemplo, con las salinas.

Sumado a ello, debemos destacar la protección de lo que se puede denominar como dominio público marítimo-terrestre estatal frente al traslado autonómico de la competencia, que ha sido reclamado por parte de algunas Comunidades Autónomas, protección que a nuestro juicio es la única posible de acuerdo con la Constitución.

\footnotetext{
${ }^{39}$ Sentencia del Tribunal Constitucional 102/1995, de 26 de junio. Fundamento Jurídico 7.
} 
Creemos que esto en particular y la Sentencia en general, puede ser calificada de contundente y fuerte, dado que cuenta con el respaldo de todos los Magistrados que conforman el Pleno del Tribunal, sin que ninguno de ellos se haya mostrado desfavorable al fallo en algún voto particular.

Junto con esto, podemos decir que se trata de un pronunciamiento coherente, manifestándose esta coherencia en una doble dirección, siendo la primera de ellas respecto de la jurisprudencia constitucional anterior, y la segunda, manteniendo la posición adoptada en torno a la norma impugnada en ulteriores pronunciamientos relativos a la misma norma.

Finalmente debemos señalar nuestra concordancia con el Tribunal Constitucional en su resolución. La actuación del Máximo Intérprete de la Lex Superior parece la más acertada si se tienen en cuenta los últimos preceptos constitucionales de los que se ha hablado en el comentario. En primer lugar, no podemos considerar que sea admisible la queja sobre el principio de irretroactividad, porque en ningún momento se está afectando a los derechos individuales de ningún ciudadano en particular, parece, únicamente una actuación por parte del demandante de querer introducir más preceptos legales para hacer la sanción más ignominiosa, si cabe.

Por otro lado, el principio de interdicción de la arbitrariedad queda roto desde el primer momento en que el ejecutivo emplea criterios distintos entre costas que a priori no tienen mayor diferencia que los intereses que algunos particulares pudieran tener. Piénsese que se considera que la Isla de Formentera pudiera presentar la marea sensible en alguna de sus riberas, cosa que no ocurre en ningún lugar del mediterráneo.

Unido al problema que supone la arbitrariedad nos vamos a encontrar con la posible brecha que va a suponer en torno a la seguridad jurídica.

Es por ello que debemos coincidir con la Sentencia del Tribunal Constitucional al declarar un acto lesivo para el medio ambiente, la falta de protección del litoral de la isla de Formentera y el mantenimiento de las depuradoras de aguas residuales. Nos parece un criterio objetivo, válido y congruente el hecho de que aquellas industrias, que no tengan más remedio que instalarse cerca o en el propio dominio marítimo-terrestre, se queden ahí situadas, pero las que no tienen esa necesidad deberían abandonarlas para poder tener en cuenta la protección ambiental del artículo 45 de la Constitución. 


\section{BIBLIOGRAFÍA}

GARCÍA PÉREZ, M., "Reflexiones sobre la Ley de Costas", Anuario da Facultade de Dereito da Universidade da Coruña, $\mathrm{n}^{\mathrm{o}}$ 13, 2009, p. 207 - 228.

GONZÁlEZ - VARAS IBÁÑEZ, S., El deslinde de las costas, Marcial Pons, Madrid, 1995.

HORGUÉ BAENA, C., El deslinde de costas, Tecnos, Madrid, 1995.

MENÉNDEZ REXACH, A., "La Ley de costas veinte años después”, VV.AA., La Ley de costas en la jurisprudencia, Ministerio de Medio Ambiente y Medio Rural y Marino, Madrid, 2010.

NOGUERA DE LA MUELA, B., Las servidumbres de la Ley de Costas de 1988, Marcial Pons, Madrid, 1995.

NúÑEZ LOZANO, M. C., La reforma de la Ley de Costas de 2013, Tirant lo Blanch, Valencia, 2013.

RIVERO ISERN, E., El deslinde administrativo, IGO, Sevilla, 1967.

RODRÍGUEZ - ARANA, J., As costas e a súa problemática, Fundación Alfredo Brañas, Santiago de Compostela, 1996.

SÁNCHEZ BLANCO, A., "La delimitación del dominio público marítimo terrestre en la Ley de costas: Incidencia de la legislación de puertos, de navegación marítima, de la normativa comunitaria sobre seguridad marítima, y del enjuiciamiento institucional del estado español por el parlamento europeo en el informe Margrete Auken", SANCHEZ GOYANES, E. (coord.), El derecho de costas en España, La Ley, Madrid, pp. 339 - 383.

TORRES ALFONSEA, F. J., "La ocupación del dominio público marítimo-terrestre en España”, Investigaciones geográficas, nº 50, 2009, pp. 63 - 91. 